\title{
Seismic Soil-Structure Interaction Analysis of Isolated Nuclear Power Plants in Frequency Domain
}

\author{
Zhiguang Zhou and Xiaodong Wei \\ College of Civil Engineering, Tongji University, Shanghai 200092, China \\ Correspondence should be addressed to Zhiguang Zhou; zgzhou@tongji.edu.cn
}

Received 25 July 2016; Revised 15 October 2016; Accepted 26 October 2016

Academic Editor: Georges Kouroussis

Copyright ( 2016 Z. Zhou and X. Wei. This is an open access article distributed under the Creative Commons Attribution License, which permits unrestricted use, distribution, and reproduction in any medium, provided the original work is properly cited.

\begin{abstract}
One important aspect of applying seismic isolation to Nuclear Power Plants (NPPs) is that the complex interactions of flexible soil, flexible isolators, and stiff structures require careful investigation. In this paper, a NPP model was used to investigate the effects of SSI and the effects of changing soil and isolator properties on seismic response of an isolated NPP. The following aspects are considered in the study: horizontal excitation and vertical excitation; linear and equivalent-linear models of the isolators; scaling of the shear modulus of the soil profile model; and scaling of the horizontal equivalent stiffness of the isolators. It was found that Pseudospectral Acceleration (PSA) in the nuclear structure at the frequencies near the natural frequency of the structure increase with elevation, and the difference between the in-structure response spectral acceleration with and without SSI effects is concentrated at the frequencies near the natural frequencies of the superstructure. It is also found that the linear SSI analysis underestimates the in-structure response of the nuclear structures compared to the equivalent-linear SSI analyses, and the soil profile properties directly affect the effectiveness of the isolation system.
\end{abstract}

\section{Introduction}

Seismic isolation has been used effectively in a number of critical applications to protect important civil infrastructure [1] and seismically isolated structures have performed as expected in major earthquakes in Japan, the US, and elsewhere $[2,3]$. As a result, there is active interest in using seismic isolation in developing new seismically resilient NPPs and related facilities [4-9].

Seismic design of isolated buildings is often performed assuming a rigid base and, consequently, the effect of SSI is ignored. This is considered reasonable by some investigators who show that although SSI has some influence on response of the structures this influence is much smaller on an isolated structure than on a nonisolated structure $[10,11]$. Other studies argue that seismic design based on the rigid base assumption is not always safe. For example, Song and Ding [12] carried out a finite element study of an isolated 9-story shear wall building. They assumed the soil was elastic but discovered that while the SSI had only modest effect on the story drifts, the isolator displacement could be somewhat bigger or smaller than predicted for a rigid base isolated building depending on the characteristics of input motion. Spyrakos et al. [13] considered a class model based on a two degree of freedom lumped mass system (representing the isolated structure) supported on a two degree of freedom system representing an elastic and deformable half-space. A parametric study was undertaken and it was concluded that the effective period and effective damping of the isolated system will shift especially for softer soils and stiff/squat structural systems that have low mass compared to a representative volume of soil interacting with the structure. The seismically isolated Christchurch Women's Hospital was shaken by a series of earthquakes in 2010 and 2011. It was noted that the displacement of the isolation system was only $2-5 \mathrm{~cm}$, which is smaller than expected for this building [14]. The investigators suggest that incorporating SSI effects can help explain this phenomenon. Mahmoud et al. [15] compared responses of isolated buildings with and without SSI under different ground motions and concluded that SSI may considerably influence the stiff superstructure response and may only slightly influence the response of more flexible 
structures. Overall, these analyses suggest that this topic is in its infancy and that additional research and development is needed.

SSI has long been a concern in the design of NPPs subjected to earthquakes $[2,16]$. Politopoulos et al. [17] and Zhou et al. [16] demonstrated that SSI may amplify the nonisolated modes' response and thus it must not be overlooked. Sayed et al. [18] demonstrated that a base isolated NPP model considering pile foundation showed higher responses than the corresponding rigidly fixed base isolated NPP model under short-period inputs, while they are less under the long-period ground motions. A special concern has been raised about the effect of SSI on the effectiveness of an isolation system. This concern arises due to the tendency of SSI to significantly lower the predominant frequencies of the excitations felt by the heavy NPP structure (and thereby reducing the effectiveness of isolation), but also because the significantly lower frequency of an isolated NPP might invalidate some previous observations regarding the effect of SSI on NPPs. Most current isolation systems are not effective in the vertical direction, so response of the plant in the vertical direction will heavily depend on SSI effects. Moreover, some isolation systems (e.g., elastomeric) have frequencies in the vertical direction which are in the frequency range of interest to structural elements and components.

Frequency domain methods have been used extensively in the past for SSI analyses of NPPs [19-22]. In this study, SASSI $[23,24]$ was used to study the effects of SSI and the effects of changing soil and isolator properties on seismic response of an isolated NPP.

\section{Equations of Motion}

The basic methods of analysis adopted by the computer program SASSI2000 are called the flexible volume and the subtraction methods. These methods are formulated in the frequency domain using the complex response method and the finite element technique $[23,24]$. In the flexible volume method used in this study, the total soil-structure system shown in Figure 1(a) is partitioned into two substructure systems as shown in Figures 1(b) and 1(c). The flexible volume method assumes that the structure consists of the superstructure plus the foundation minus the excavated soil. The equations of motion for the total system shown in Figure 1(a) can be written in the following matrix form:

$$
\begin{gathered}
{\left[\begin{array}{cc}
C_{s s} & C_{s i} \\
C_{i s} & \left(C_{i i}-C_{f f}+X_{f f}\right)
\end{array}\right]\left\{\begin{array}{l}
u_{s} \\
u_{f}
\end{array}\right\}} \\
=\left\{\begin{array}{c}
0 \\
X_{f f} u_{f}^{i}
\end{array}\right\}+\left\{\begin{array}{l}
P_{x s} \\
P_{x f}
\end{array}\right\}=\left\{\begin{array}{l}
P_{s} \\
P_{f}
\end{array}\right\} .
\end{gathered}
$$

Subscripts $s, i$, and $f$ are used to refer to degrees of freedom associated with the nodes on the superstructure, basement, and excavated soil, respectively. $u$ is the complex Fourier coefficients of the modal displacement solution. $X_{f f}$ is a frequency-dependent matrix representing the dynamic stiffness of the foundation at the interaction nodes and is called the impedance matrix. Moreover, $P_{s}$ and $P_{f}$ are the net forces at the superstructure and foundation nodes, respectively, with $P_{x s}$ and $P_{x f}$ denoting the amplitudes of the external forces at those nodes. $[C]$ is a complex frequency-dependent dynamic stiffness matrix:

$$
[C]=[K]-\omega^{2}[M],
$$

where $[M]$ and $[K]$ are the total mass and stiffness matrices, respectively.

As indicated by these equations, for each frequency, $\omega$, the impedance matrix, the load vector, and the dynamic stiffness matrices for the structure and the excavated soil are formed. After forming the equations of motion, they could be solved. The main steps for a standard solution of a SSI problem include forming dynamic stiffness of structure, forming dynamic stiffness of excavated soil, forming impedance matrix, forming the total stiffness of the system, triangularization, forming load vector, and solution of the equations.

\section{The Base Isolated Nuclear Power Plant Model}

A model representing a Generation III Pressurized Water Reactor (PWR) NPP is illustrated in Figure 2. The Nuclear Island consists of the Reactor Containment Building (RCB) and the Auxiliary Building, which share a common base mat. The shape of the Auxiliary Building is a rectangular type with maximum dimensions of $103.6 \mathrm{~m} \times 102.4 \mathrm{~m}$. It wraps around the RCB with a gap equal to $5 \mathrm{~cm}$ and the radius of circular cavity for the RCB is $24 \mathrm{~m}$. The RCB consists of the Containment Shell, Reactor Containment Internal Structures, and Reactor Coolant Systems. The wall thickness of the RCB and Auxiliary Building is $122 \mathrm{~cm}$ and $137 \mathrm{~cm}$, respectively. The first horizontal frequency and the first vertical frequency of the Containment Shell are $3.85 \mathrm{~Hz}$ and $11.02 \mathrm{~Hz}$, respectively, which are obtained using the stick model of the Containment Shell with the bottom node fixed. The first horizontal frequency and the first vertical frequency of the Secondary Shield Wall (representative of the Internal Structures) are $13.00 \mathrm{~Hz}$ and $29.65 \mathrm{~Hz}$, respectively. There are 219 lead rubber bearing elements in the model. The isolators have an effective period of $2.0 \mathrm{~s}$ based on a maximum displacement of $15 \mathrm{~cm}$ under the design basis earthquake. The properties correspond to the design of the bearings are shown in Figure 2(d). The isolators are assumed elastic in SASSI except that the equivalent-linear method is used for the isolators in Section 4.2.

The generic site soil profile used in the analyses is illustrated in Figure 3. In order to study the effect of site response on SSI, the S-wave and P-wave velocities (i.e., corresponding moduli) were scaled upwards and downwards; specifically, the shear modulus $G$ of soil was halved and doubled ( $0.5 G, G$, $2 G)$, which makes the top soil layer corresponding to medium soil, hard soil, and rock, respectively. Although general NPPs were set on rock sites, isolated NPPs are supposed to be set on medium soil sites. 




(a) Total system

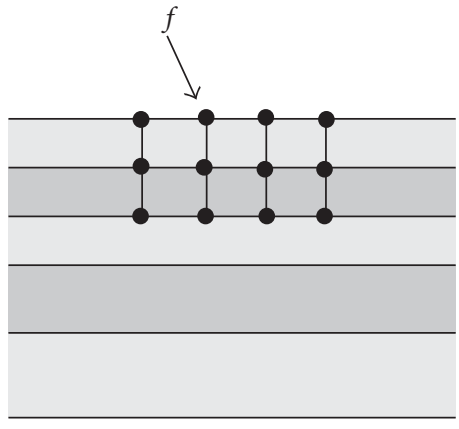

$f=$ excavated soil volume node

(b) Foundation

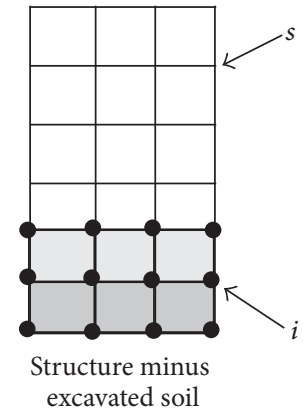

$s=$ superstructure node

$i=$ basement node

(c) Structure

FIgURE 1: Substructuring in the flexible volume method.

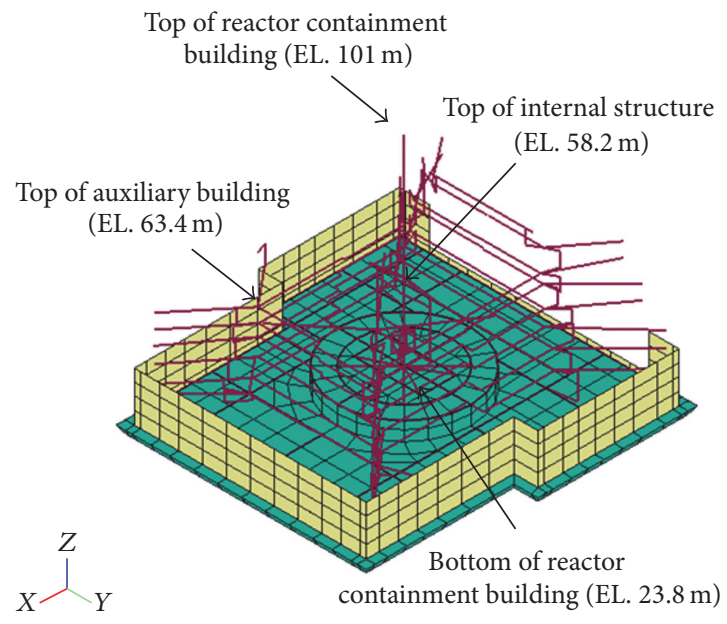

(a) $3 \mathrm{D}$ view of the superstructure model

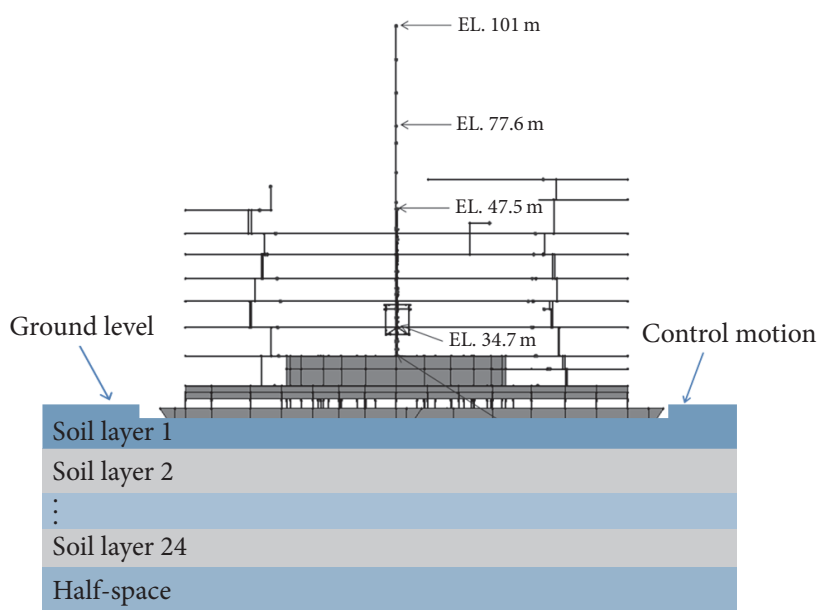

(b) Elevation drawing of the total system



(d) Hysteretic curve of lead rubber bearings

(c) Layout of lead rubber bearings

Figure 2: SASSI Model (EL: elevation level). 


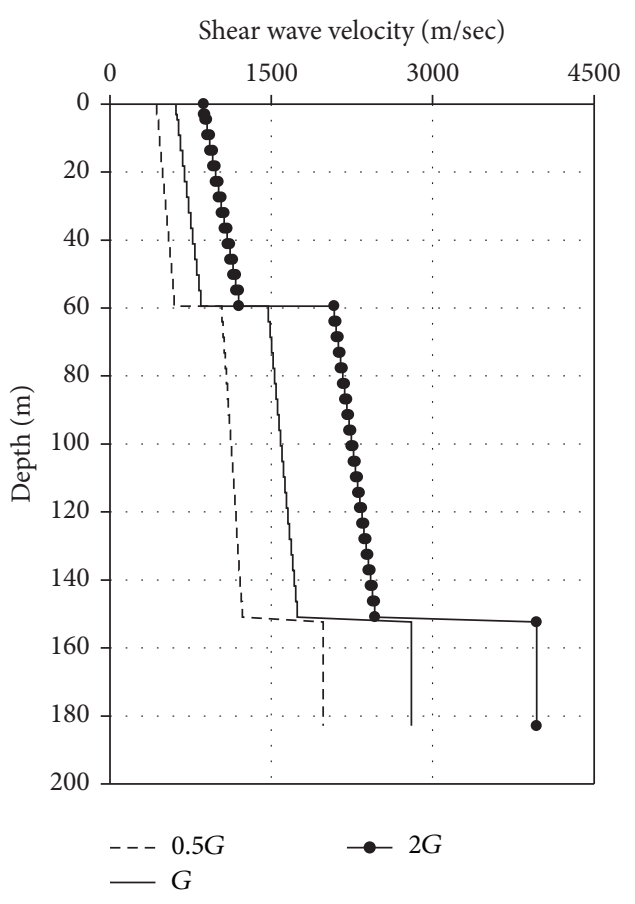

Figure 3: Soil profile.

In SASSI, the control motion was set for the ground surface, which has an elevation of $11.48 \mathrm{~m}$. According to the characteristics of SASSI, unidirectional ground motion was input for each analysis. The isolated NPP was designed to have a Safe Shutdown Earthquake (SSE) of $0.5 \mathrm{~g}$. The input motions are illustrated in Figure 4. A synthetic time history M1 in the horizontal direction, which was synthetically generated to be consistent with the European Utility Requirements for LWR Nuclear Power Plants and have $0.5 \mathrm{~g}$ of Peak Ground Acceleration (PGA), is illustrated in Figure 4(a). The corresponding synthetic time history M3 in the vertical direction, with the PGA being $2 / 3$ times of $0.5 \mathrm{~g}$, is illustrated in Figure 4(b). As illustrated in Figure 4(c), one horizontal motion recorded at Nishi-Akashi during the Kobe earthquake was also used. The Kobe motion has approximately the same PGA as the M1 motion.

\section{Horizontal Excitation Analysis}

4.1. Comparison of Response Spectra with and without SSI Effects. To study the effects of SSI on the seismically isolated NPP, it is necessary to compare the results of one model with SSI and another model without SSI. Because the frequency domain method uses the so-called complex stiffness modulus to represent damping forces, while viscous damping is used in time domain analysis, it was decided to set both models in the frequency domain code SASSI. For the model with SSI effects taken into account, the soil profile with shear modulus $G$ illustrated in Figure 3 was used as the input to perform the free-field site response analysis using the computer program SHAKE91 [25]. Then, the average strain-compatible soil properties from the site response analysis were used as the soil model in SASSI. For the model without SSI effects, the fixed base structure was modelled by setting the soil layer to a low thickness (e.g., $0.3 \mathrm{~m}$ ) and high stiffness, as well as by removing the half-space under the soil layer. The equivalent bearing stiffness was used in the analysis. The damping ratio used for the response spectral analyses was set to $5 \%$.

Comparison of the $5 \%$ damped response spectral acceleration (Pseudospectral Acceleration, PSA) with and without SSI effects for the top of the RCB and input motion is illustrated in Figure 5. Figure 5(a) shows the value of PSA, while Figure 5(b) shows the normalized PSA with respect to the PSA of the input motions. Figure 6 shows the normalized PSA with respect to the PSA of the upper mat above the isolators. The difference between the results with and without SSI effects is obvious at frequencies near $3.5 \mathrm{~Hz}$ and $11 \mathrm{~Hz}$ for M1 motion and at the frequency near $4 \mathrm{~Hz}$ for the Kobe motion, which corresponds to the first $(3.85 \mathrm{~Hz})$ and second $(11.02 \mathrm{~Hz})$ modal frequencies of the Containment Shell. Although the M1 motion and the Kobe motion have the same PGA, it can be observed that the Kobe motion produces a relatively large response spectral acceleration at a frequency of approximately $4 \mathrm{~Hz}$. The M1 motion produces a relatively large difference between the results without and with SSI effects. Relative to the PSA of the upper mat, the PSA at the top of the RCB is amplified at all frequencies shown in Figure 6 and notably amplified at frequencies near the natural frequency of the Containment Shell.

Comparison of the response spectral displacement for the top of the RCB and input motion is illustrated in Figure 7. Isolation reduces the response spectral displacement for almost all of the frequency ranges under the Kobe motion; however, this is not the case for the M1 motion. The spectral displacement results without and with SSI effects exhibit a limited difference at a frequency of approximately $2 \sim 4 \mathrm{~Hz}$.

Figure 8 shows the response spectral acceleration for different elevations of the RCB under horizontal excitation M1. It can be observed that the in-structure response acceleration in the RCB at the frequencies near $3.5 \mathrm{~Hz}$ and $11 \mathrm{~Hz}$ increases with elevation. It can also be observed that the SSI effects enlarge the amplification of the response spectral acceleration along the elevation at a frequency near the natural frequency of the RCB.

From the above discussions, it can be concluded that the difference between the in-structure response spectral acceleration with and without SSI effects is concentrated at the frequencies near the natural frequency of the superstructure and that SSI effects enlarge the response spectral acceleration at these frequencies.

A direct integration analysis of the NPP model in ABAQUS with nonlinear isolation properties was performed for having a consistent comparison with the employed frequency domain analyses in SASSI. Comparison of results between frequency domain (SASSI) and time domain (ABAQUS) for the top of the RCB is illustrated in Figure 9. Figure 9(a) shows the response spectral acceleration with and without SSI considered. Figure 9(b) shows the ratio between the PSA results with and without SSI effects. Both time domain and frequency domain analyses show the trend that SSI effects enlarge the amplification of the response spectral acceleration near the natural frequency of the RCB, 


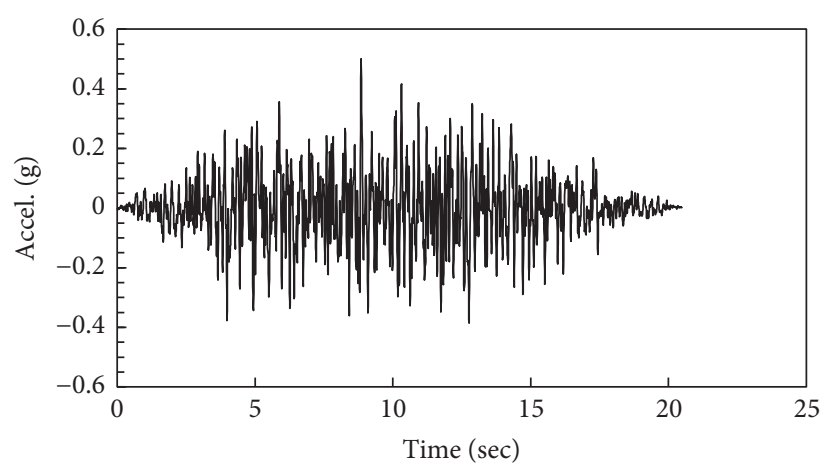

(a) M1 (synthetic, horizontal)



(b) M3 (synthetic, vertical)

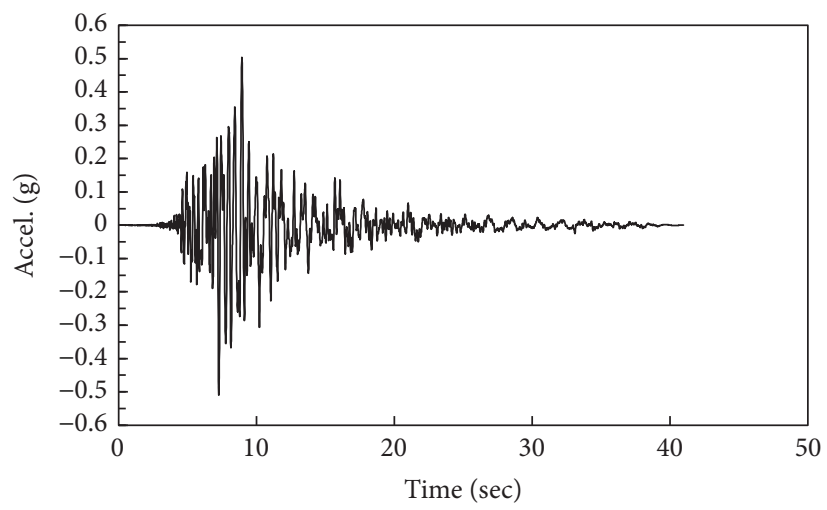

(c) Kobe/Nis (recorded, horizontal)

FIGURE 4: Input motions.

while time domain analysis shows a larger PSA value than frequency domain analysis. This is considered to be due to the nonlinear bearing model adopted in time domain analysis which is closer to reality. Although the difference exists between time domain and frequency domain analyses, it can be seen from Figure 9 that frequency domain analysis can predict the frequencies where SSI effects amplify the PSA results and the ratio between the PSA results with and without SSI effects. Considering that time domain analysis is more time consuming than frequency domain analysis, it is meaningful to investigate the seismic SSI response of isolated NPP models by frequency domain analysis.

4.2. SSI Analysis Using the Equivalent-Linear Method. As the displacement of bearings varies under excitation, it is expected that using the fixed horizontal stiffness corresponding to the design displacement is not always safe. It is necessary to consider the different stiffness values at different displacements. Considering that SASSI is a standard linear software for SSI analysis of NPP structures, it is meaningful to adapt an iterative procedure of the equivalent-linear method to the analysis of isolated NPPs.

The NPP model was used to perform an iterative study for input motion M1. The two types of characteristic response displacements of the bearings were used to calculate the effective stiffness and damping ratio of the bearings in the iteration procedure, as illustrated in Figure 10, until the error between the equivalent stiffness used in the current step and the calculated stiffness using the maximum/equivalent displacement was less than $1 \%$. The goal was to determine the correct equivalent stiffness such that the maximum/equivalent displacement of the bearings was equal to the displacement used to calculate the equivalent stiffness from the bilinear model of the bearings.

A comparison of the response spectral acceleration of the noniteration analysis and the iteration analyses with the maximum displacement and the equivalent displacement used as the characteristic response displacement of the bearings is illustrated in Figure 11. It can be observed that the noniteration analysis underestimates the in-structure response of the NPP structures, especially at frequencies near the natural frequency of the isolation system. The periods of the bearings corresponding to the noniteration analysis, the iteration analysis using maximum displacement, and the iteration analysis using equivalent displacement are 2 seconds, 1.85 seconds, and 1.71 seconds, respectively. It can also be observed that the noniteration analysis yields the smallest value and that the values from the iteration analysis using the maximum displacement as the iteration variable are lower for some frequency ranges and greater for other frequency ranges than those from the iteration analysis using equivalent displacement as the iteration variable. A comparison of the response spectral displacement for the different analysis methods is illustrated in Figure 12. At a frequency of approximately $0.5 \mathrm{~Hz}$, the results from the iteration analysis using the maximum displacement as the 


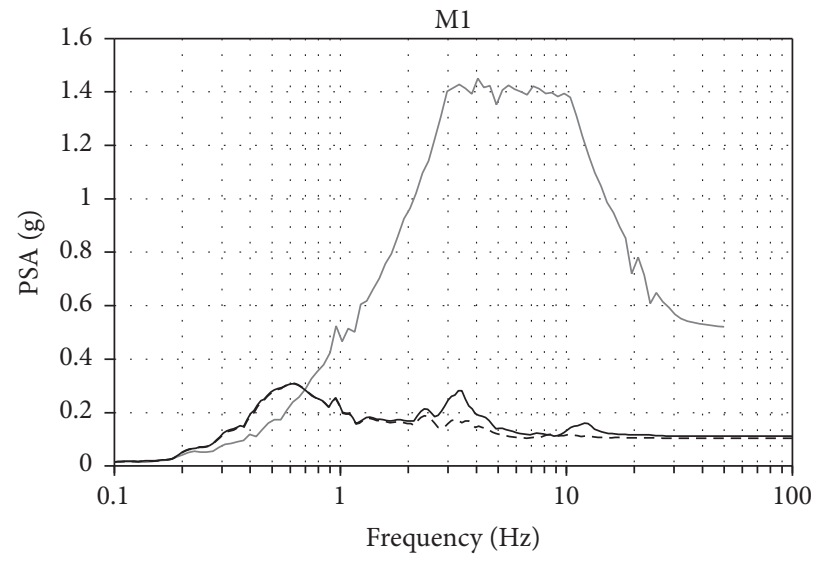

- Input motion _ With SSI effects

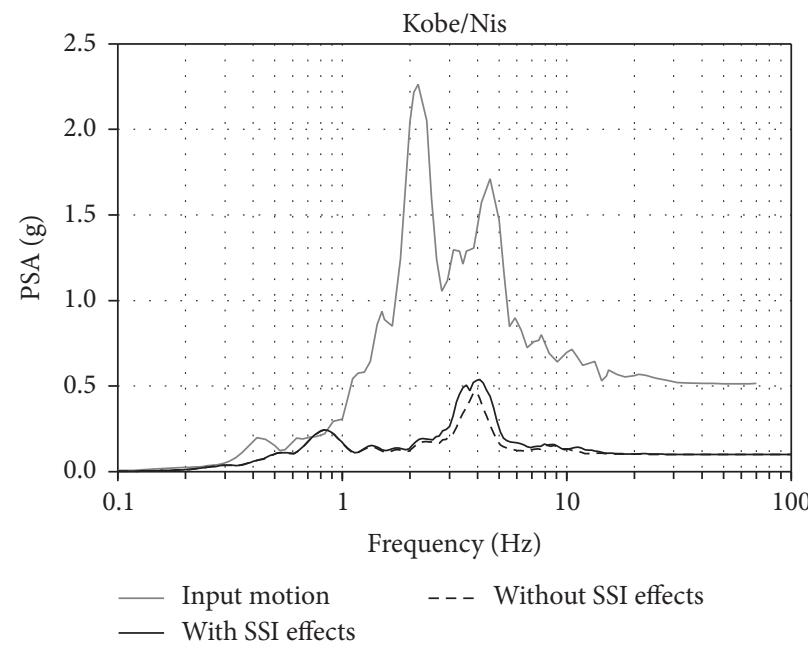

(a) Response spectral acceleration
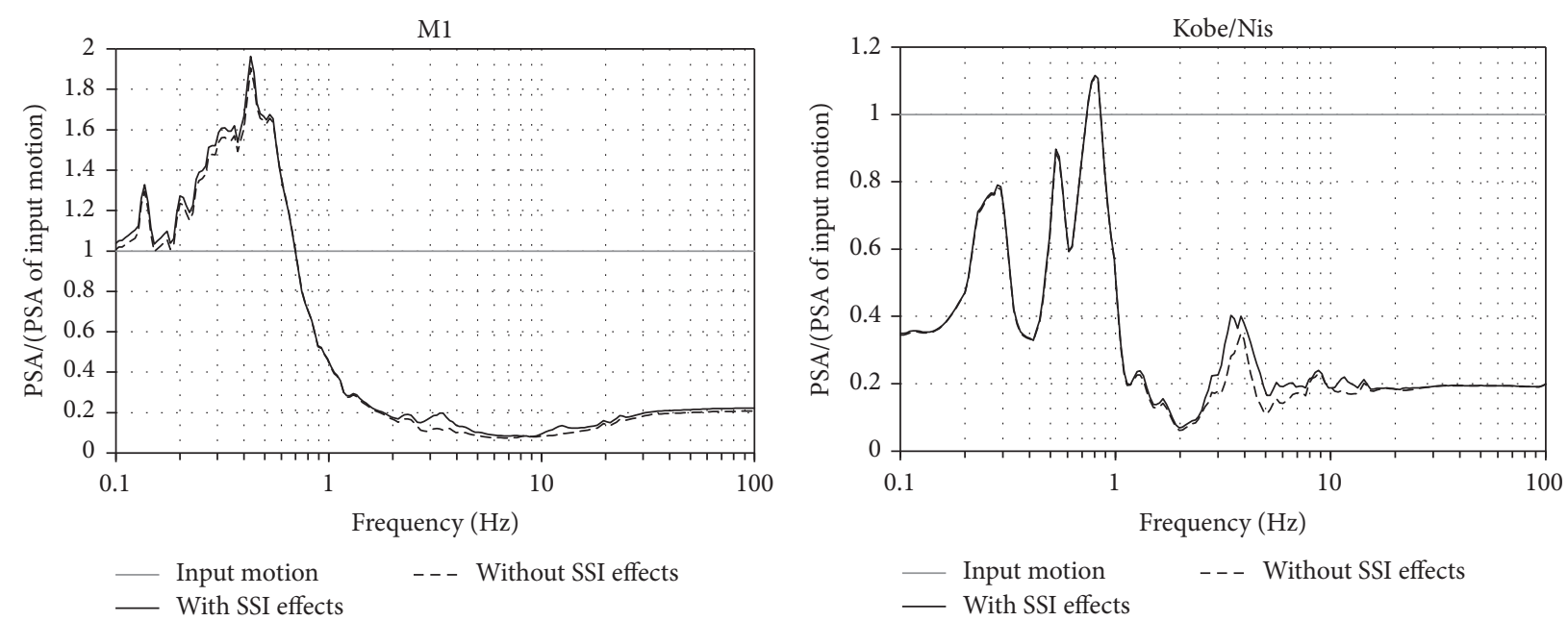

(b) Normalized response spectral acceleration with respect to PSA of input motion

FIgURE 5: Comparison of the response spectral acceleration for the top of the Reactor Containment Building and input motion.

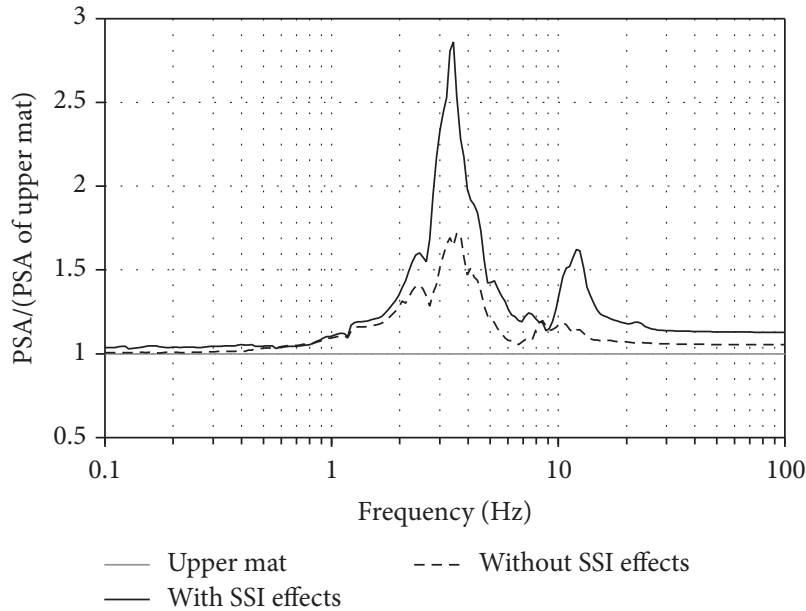

(a) M1

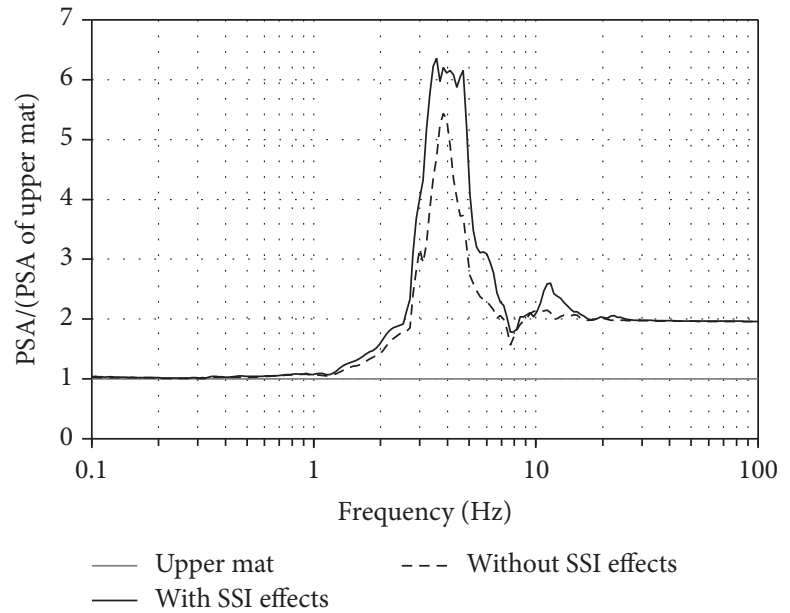

(b) Kobe/Nis

FiguRE 6: Comparison of the normalized response spectral acceleration for the top of the RCB and the upper mat. 


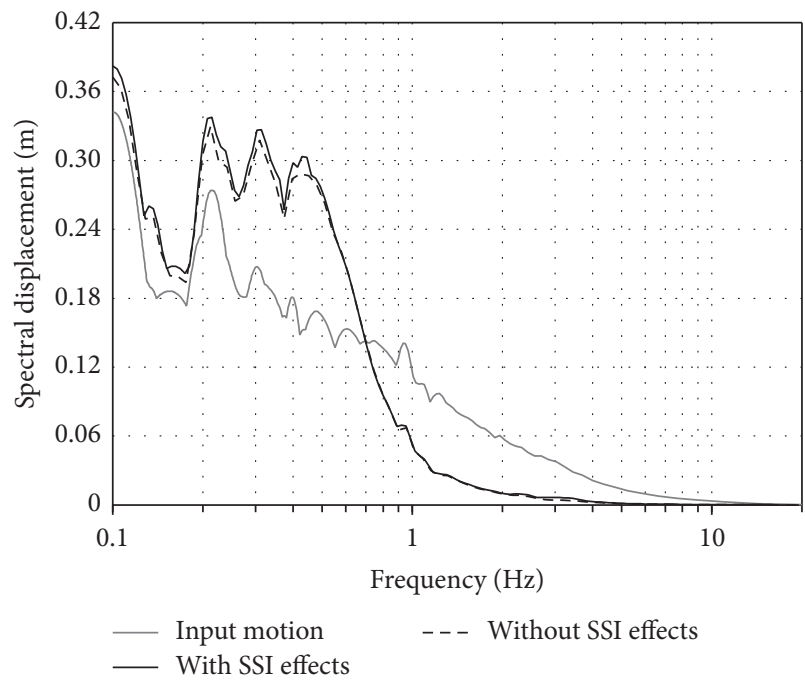

(a) M1

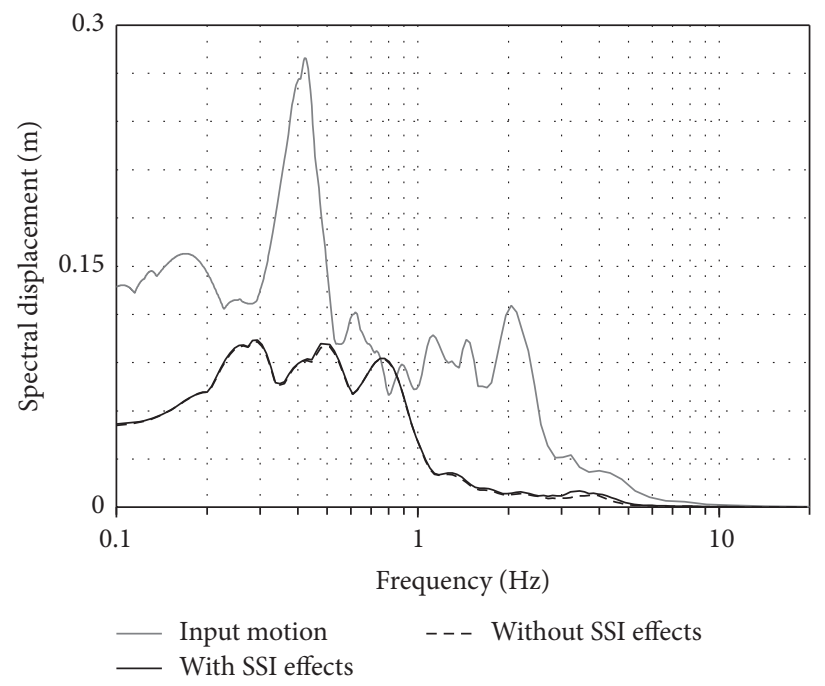

(b) Kobe/Nis

Figure 7: Comparison of the response spectral displacements for the top of the Reactor Containment Building and input motion.

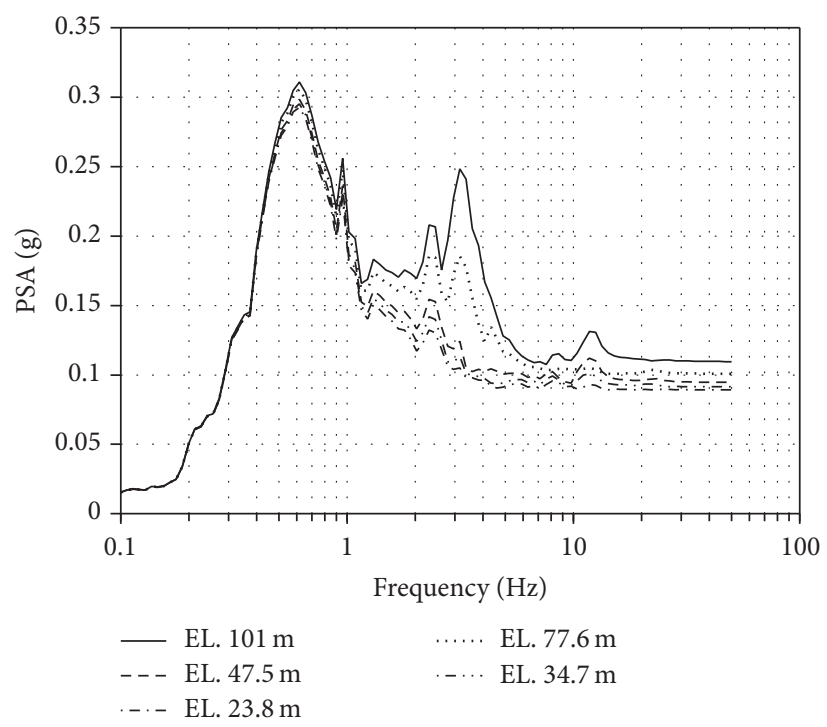

(a) With SSI effects

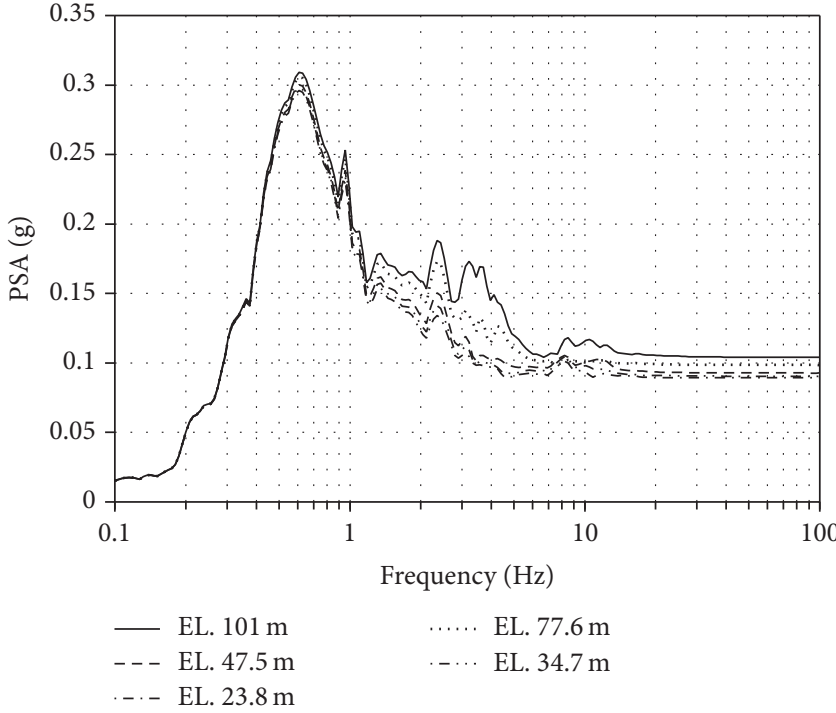

(b) Without SSI effects

FIgURE 8: Response spectral acceleration for different elevations of the Reactor Containment Building under horizontal excitation M1.

iteration variable are greater than those from the other two analysis methods. For frequencies greater than $1 \mathrm{~Hz}$, which is of interest for in-structure response analysis, the response spectral displacement of the different analysis methods showed limited differences.

4.3. The Effect of Changing the Shear Modulus of the Soil. The S-wave velocity and P-wave velocity of the original soil profile model were scaled upwards and downwards, as shown in Figure 3, to study its effects on seismic response of the superstructure under the motion M1. Other portions of the model were unchanged, that is, the superstructure, the bearings and the control motion were the same throughout.

The PSA and the spectral displacement at the top and the bottom of Reactor Containment Building are illustrated in
Figures 13 and 14, respectively. While the spectral displacements of the two positions show minor difference when the shear modulus of soil changes, the PSA at the top of RCB shows big difference at the frequencies near $3.85 \mathrm{~Hz}$ and $11 \mathrm{~Hz}$, which corresponds to the first and second mode frequency of the Containment Shell. It can also be seen that reducing the shear modulus of soil results in increasing the amplification of PSA from the bottom to the top. These results demonstrate that the effectiveness of the isolation system is affected by the property of the soil profile.

4.4. The Effect of Changing Horizontal Equivalent Stiffness of Bearings. Horizontal equivalent stiffness of the bearings was scaled to study its effect on PSA. The scaled horizontal equivalent stiffness values are illustrated in Table 1. When 




(a) Response spectral acceleration

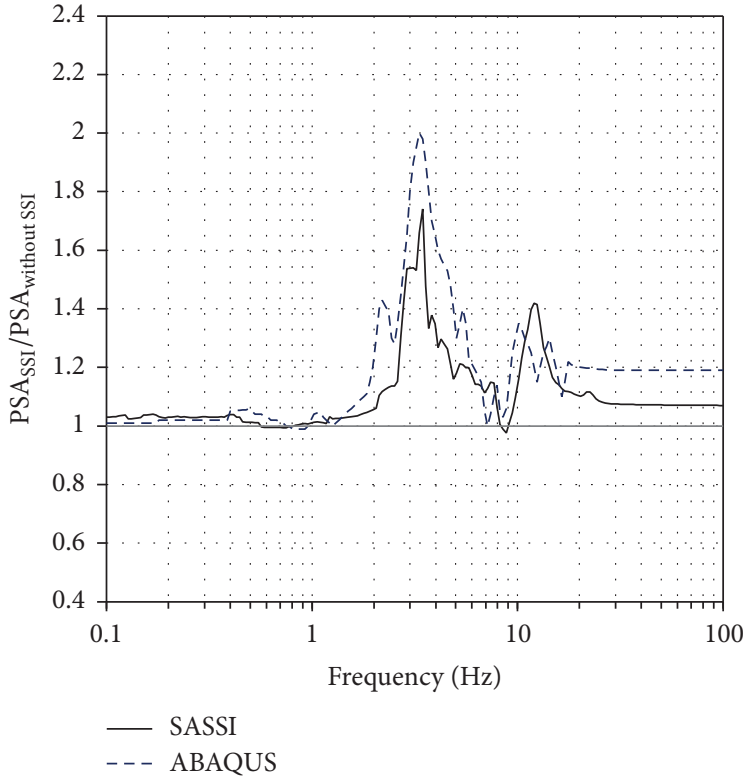

(b) Ratio between the results with and w/o SSI effect

FIGURE 9: Comparison of results between frequency domain (SASSI) and time domain (ABAQUS) for the top of the Reactor Containment Building.

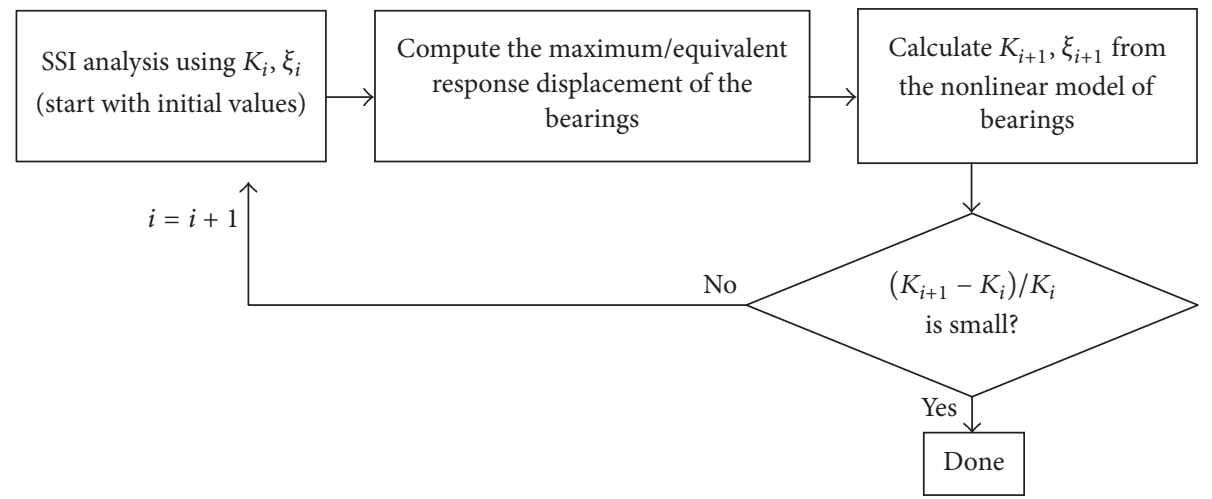

FIGURE 10: Flowchart of the iteration procedure using the equivalent-linear method.

TABLE 1: Scaled horizontal equivalent stiffness of the bearings.

\begin{tabular}{lcc}
\hline Scale factor of the stiffness & Frequency of the bearings & Period \\
\hline 0.44 & 0.33 & 3.0 \\
1.00 & 0.50 & 2.0 \\
1.78 & 0.67 & 1.5 \\
4 & 1.0 & 1.0 \\
256 & 8.00 & 0.13 \\
\hline
\end{tabular}

the horizontal frequency of the bearings becomes $8 \mathrm{~Hz}$, it corresponds to the case without isolation. The effect of changing horizontal equivalent stiffness on PSA at the top node and the bottom node of the RCB are illustrated in Figures 15(a) and 15(b), respectively. It can be seen that the frequency at which the maximum PGA occurs shifts from case to case and that the in-structure response can be amplified with high horizontal equivalent stiffness. The PSA comparison at different elevations for bearing frequencies of $0.5 \mathrm{~Hz}$ and $8 \mathrm{~Hz}$ are illustrated in Figure 16. The results show that PSA at the frequencies near the natural frequency of the structure increase with elevation for both cases, while the amplification factor is different. Actually, bearing frequency of $8 \mathrm{~Hz}$ represents a nonisolated model; it can be seen that isolation decreases the amplification factor.

\section{Vertical Excitation Analysis}

5.1. Comparison of Response Spectra with and without SSI Effects. Vertical motion M3 was input to study the SSI effects in the vertical direction. The plots of $5 \%$ damped PSA at different elevations of the RCB under vertical excitation are 


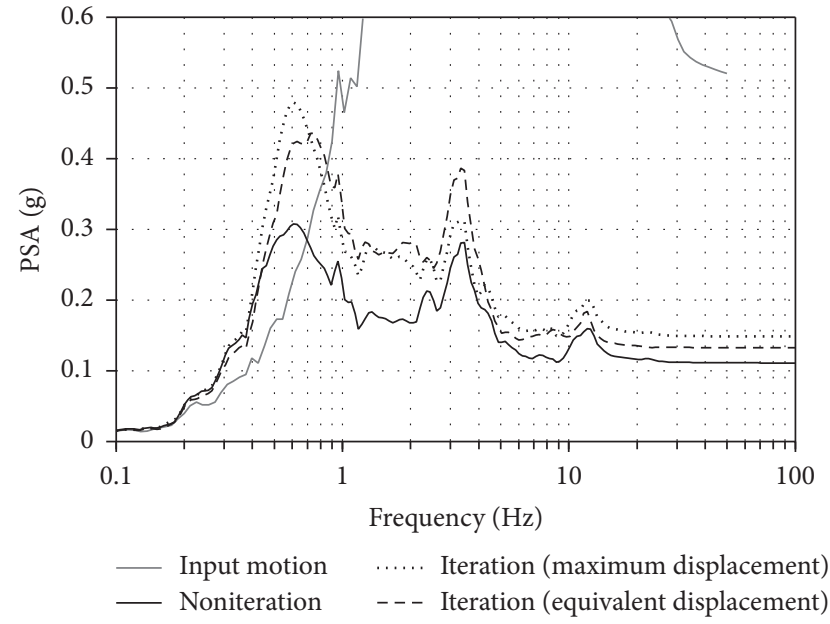

(a) At the top of the Reactor Containment Building

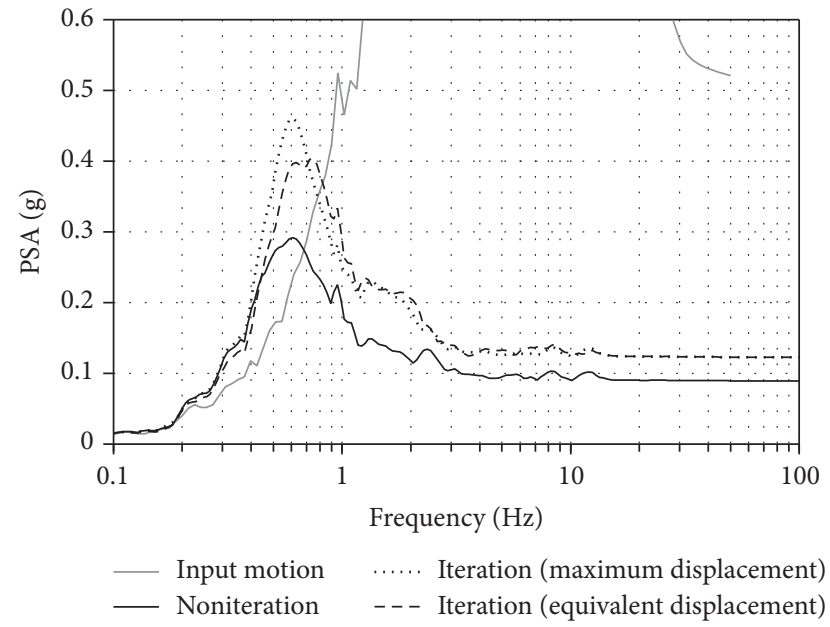

(b) At the bottom of the Reactor Containment Building

FIGURE 11: Comparison of the response spectral acceleration for different analysis methods.

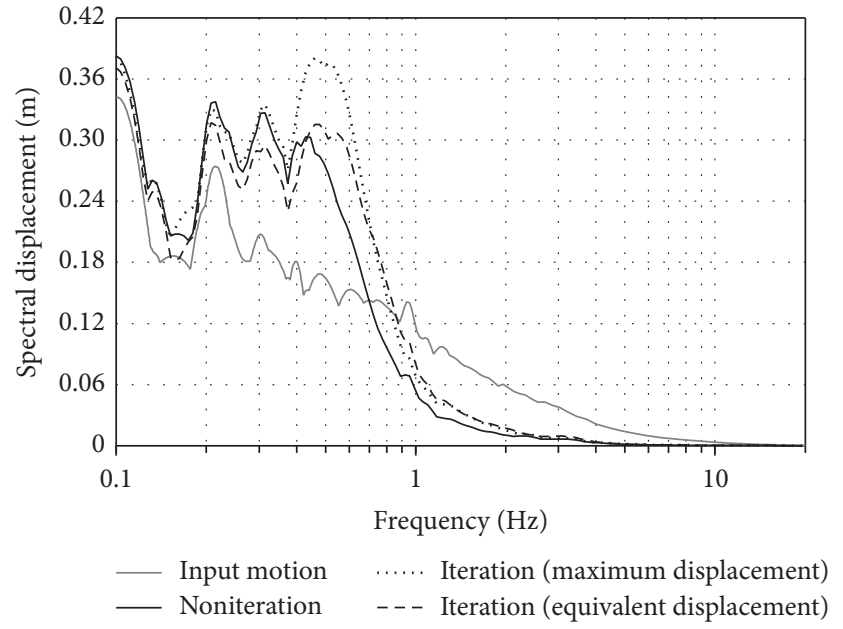

(a) At the top of the Reactor Containment Building



(b) At the bottom of the Reactor Containment Building

FIGURE 12: Comparison of the response spectral displacement for different analysis methods.

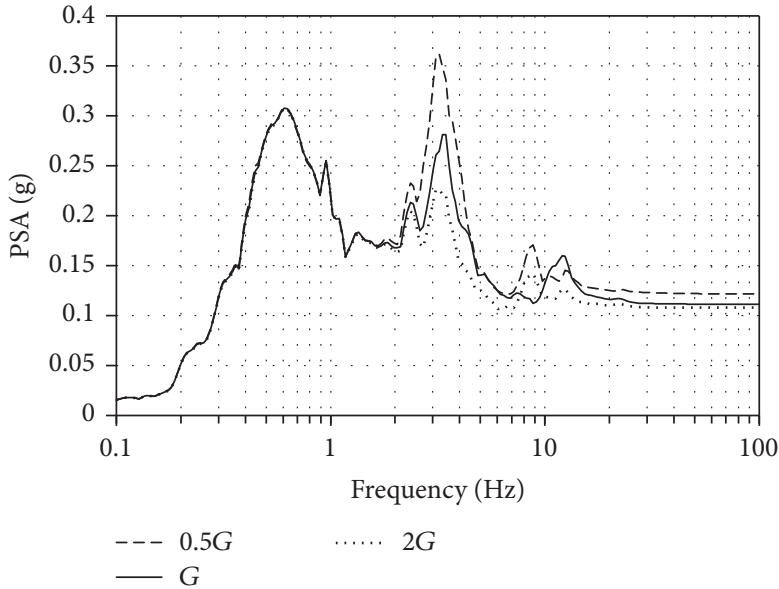

(a) At the top of Reactor Containment Building



(b) At the bottom of Reactor Containment Building

FIGURE 13: Comparison of response spectra acceleration under horizontal excitation for different soil shear modulus. 


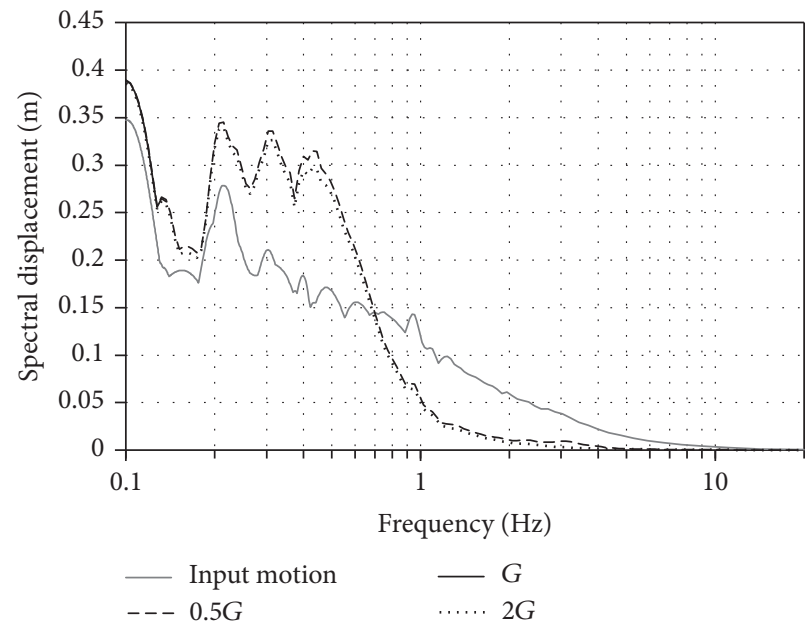

(a) At the top of Reactor Containment Building



(b) At the bottom of Reactor Containment Building

FIGURE 14: Comparison of response spectra displacement under horizontal excitation for different soil shear modulus.



(a) At the top node of RCB

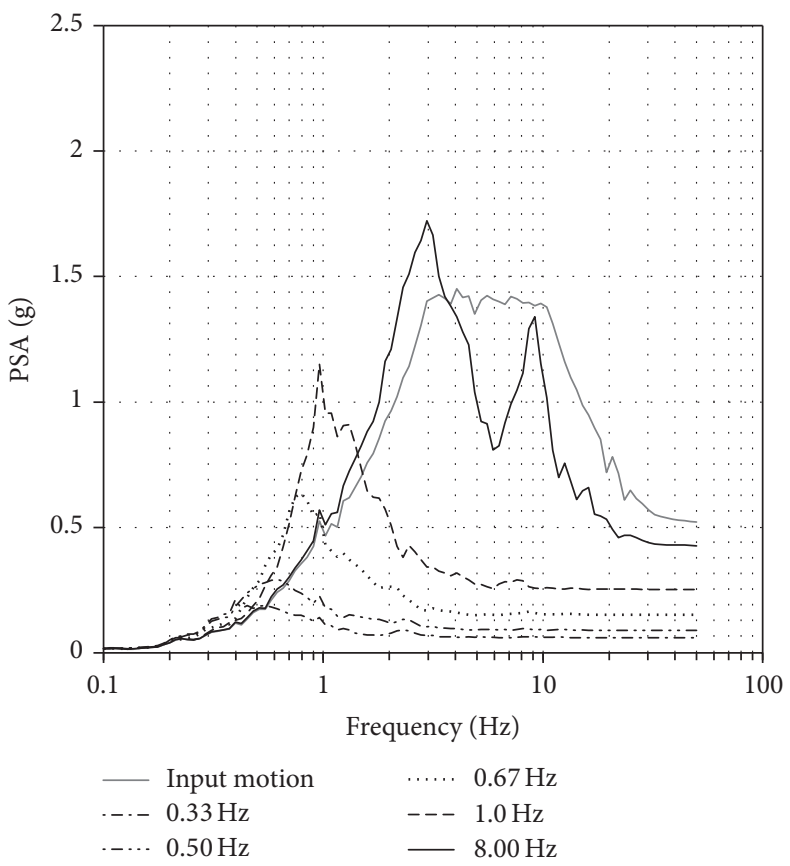

(b) At the bottom node of RCB

FIGURE 15: Effect of changing horizontal equivalent stiffness of bearings on PSA.

presented in Figure 17. A comparison of the PSA with and without SSI effects for two specific positions and the input motion M3 is illustrated in Figure 18. It can be concluded that considering the SSI effects results in a reduction of the PSA for a majority of the frequency range. This suggests that soil acts as an isolation system in the vertical direction to a certain degree. Moreover, it can be observed that the instructure response for the RCB near $10 \mathrm{~Hz}$ is highly amplified by the seismic motion. This differs from the corresponding results obtained for the horizontal direction, although the instructure response near $3.5 \mathrm{~Hz}$ increases with the elevation in the horizontal direction. It is clear that the amplification of the floor spectra in the vertical direction at frequencies corresponding to the vertical direction modes of the fixed base structure and substantial deamplification of the horizontal floor spectra over a broad frequency range will be expected.

The 5\% damped response spectral displacement at different elevations of the RCB is illustrated in Figure 19. A comparison of the response spectral displacement with and without SSI effects for the two specific positions and input motion is illustrated in Figure 20. It can be seen that the difference between the in-structure response spectral 


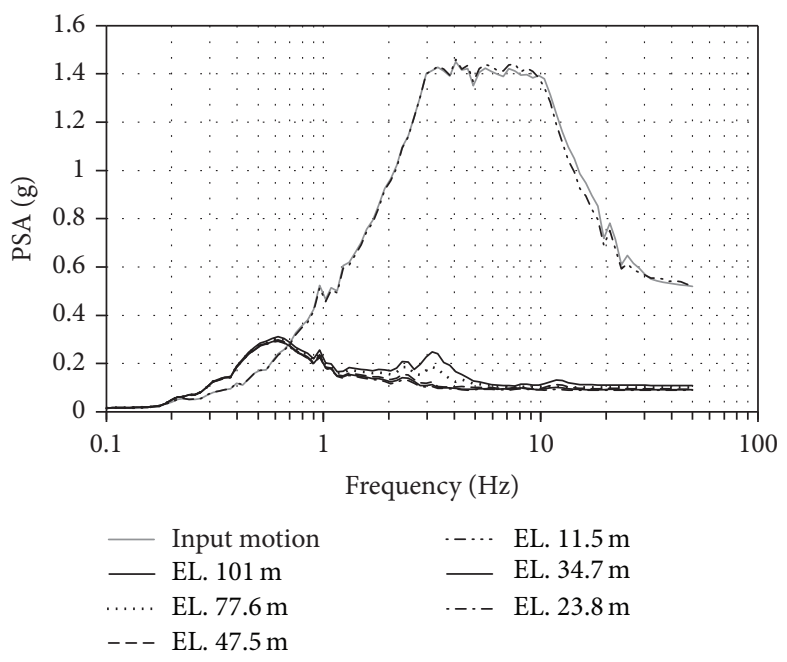

(a) Horizontal frequency of bearing $=0.5 \mathrm{~Hz}$

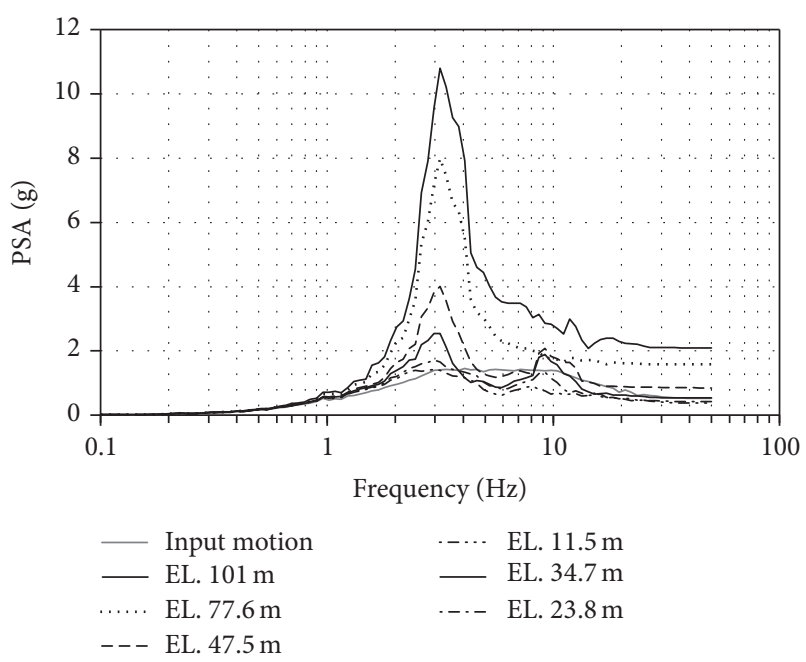

(b) Horizontal frequency of bearing $=8 \mathrm{~Hz}$

FIGURE 16: PSA comparison at different elevation.



(a) With SSI effects

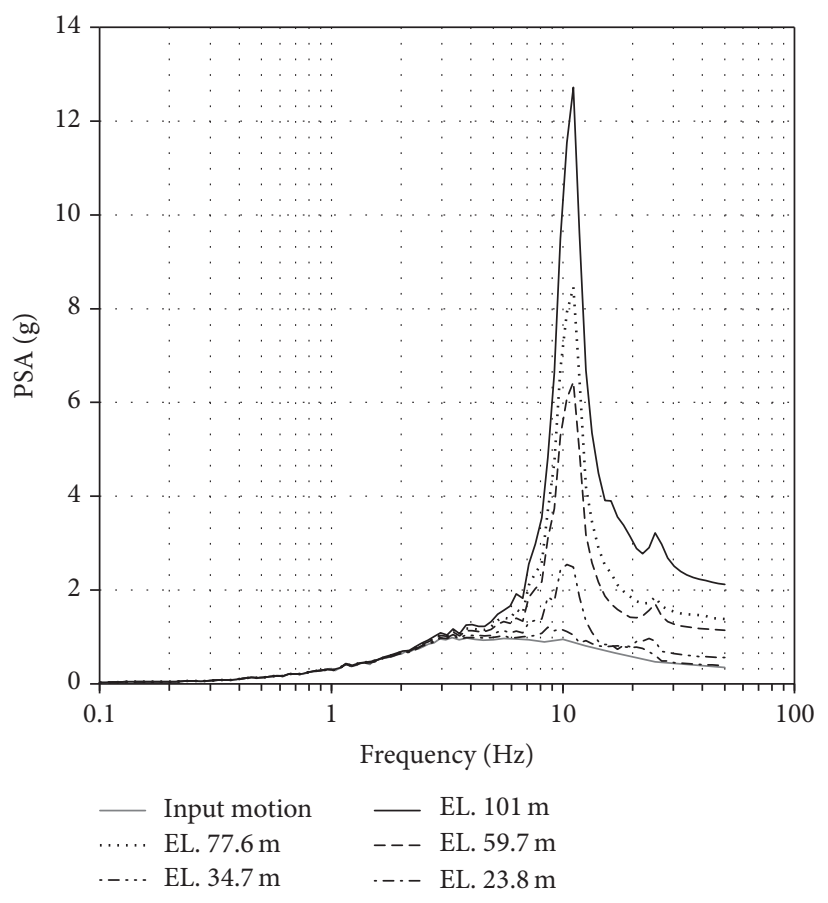

(b) Without SSI effects

FIGURE 17: The response spectral acceleration for different elevations of the Reactor Containment Building and vertical motion input.

displacement with and without SSI effects is concentrated at the frequencies near $11 \mathrm{~Hz}$ and $3 \mathrm{~Hz}$, which correspond to the natural frequencies of the structure and the soil field frequency. The SSI effects enlarge the response spectral displacement at the soil field frequency, while reducing the response spectral displacement at the natural frequencies of the structure.

5.2. The Effect of Changing the Shear Modulus of the Soil. The PSA and the spectral displacement at the two specific positions are shown in Figures 21 and 22, respectively. The spectral displacement at the two positions shows limited differences when the shear modulus of soil changes. As the frequencies, at which the PSA is amplified, change from one soil profile to another, no obvious trend can be seen from Figure 21. Nevertheless, it can be concluded from Figure 21 that reducing the shear modulus of soil results in reduction of the PSA over much of the frequency range. This means that softer soil acts as an isolation system in the vertical direction to a certain degree. 


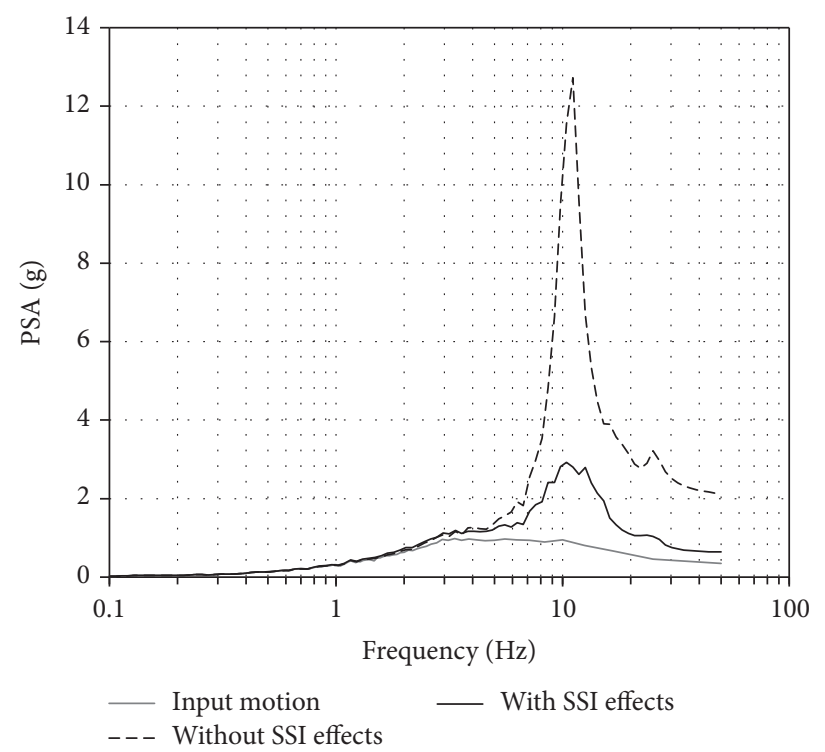

(a) At the top of the Reactor Containment Building

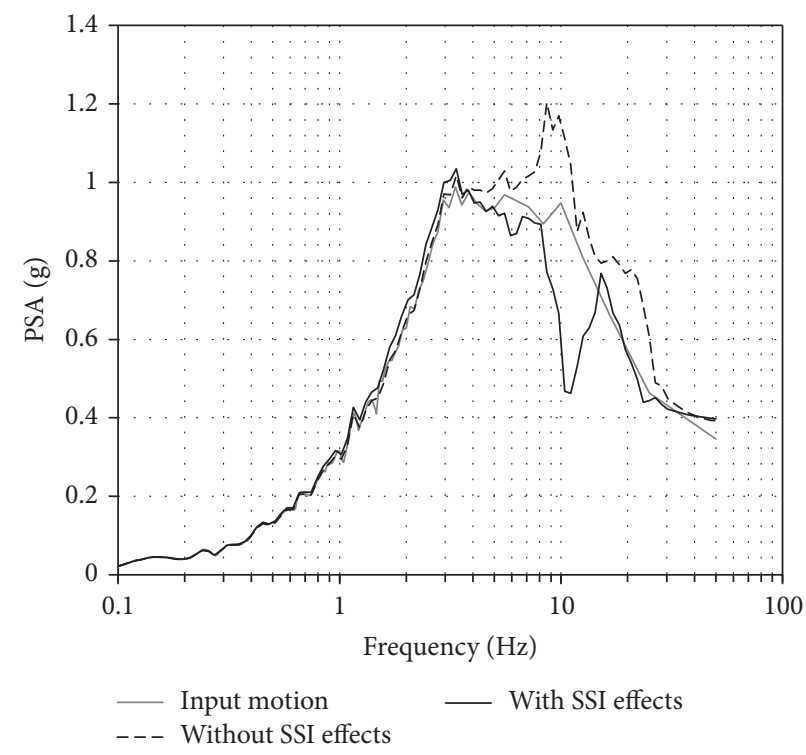

(b) At the bottom of the Reactor Containment Building

FIGURE 18: Comparison of the response spectral acceleration with and without SSI effects under vertical excitation.

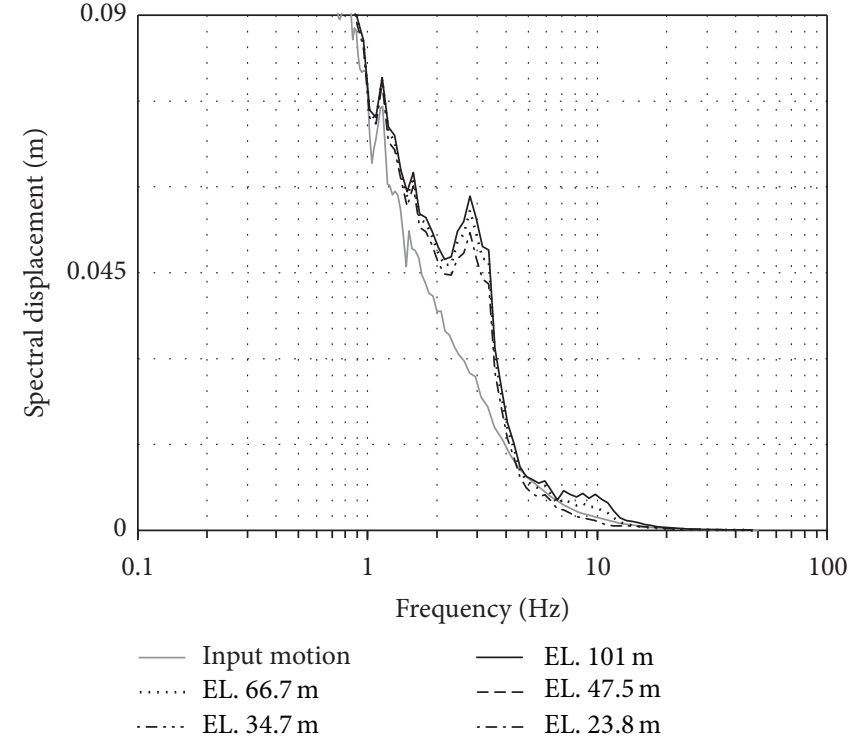

(a) With SSI effects

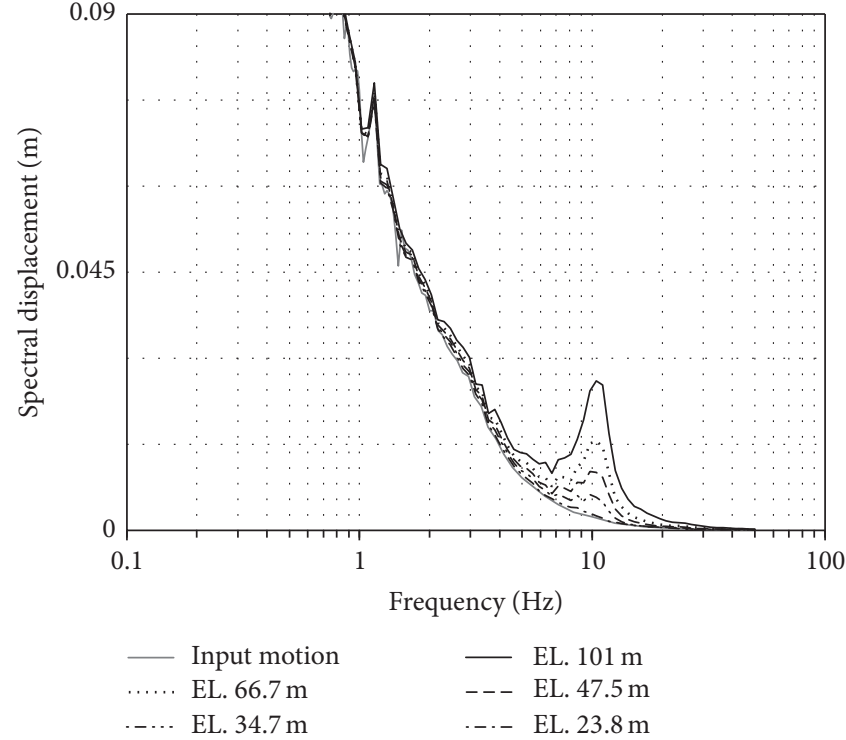

(b) Without SSI effects

FIGURE 19: The response spectral displacement for different elevations of the Reactor Containment Building and vertical motion input.

\section{Conclusions}

A model representing a standard modern Pressurized Water Reactor (PWR) NPP was used to investigate the effects of Soil-Structure Interaction on seismically isolated plants. Moreover, in order to evaluate the effect of changing the shear modulus of soil on the seismic response, the S-wave velocity and $\mathrm{P}$-wave velocity of the original soil profile model were first scaled upwards and downwards; specifically, the shear modulus of soil was taken as half or double that of the original modulus, while other portions of the model were unchanged. The results show the following.
(1) For the horizontal excitation, a substantial deamplification of the horizontal floor spectra over a broad frequency range was expected in terms of the effectiveness of isolation for NPPs. In regard to the SSI effects on the seismic response of NPPs, the difference between the in-structure response spectral acceleration with and without SSI effects is concentrated at frequencies near the natural frequencies of the structure. It is observed that the SSI effects enlarge the response spectral acceleration at these frequencies. Different from the response spectral acceleration, there is a limited difference between 


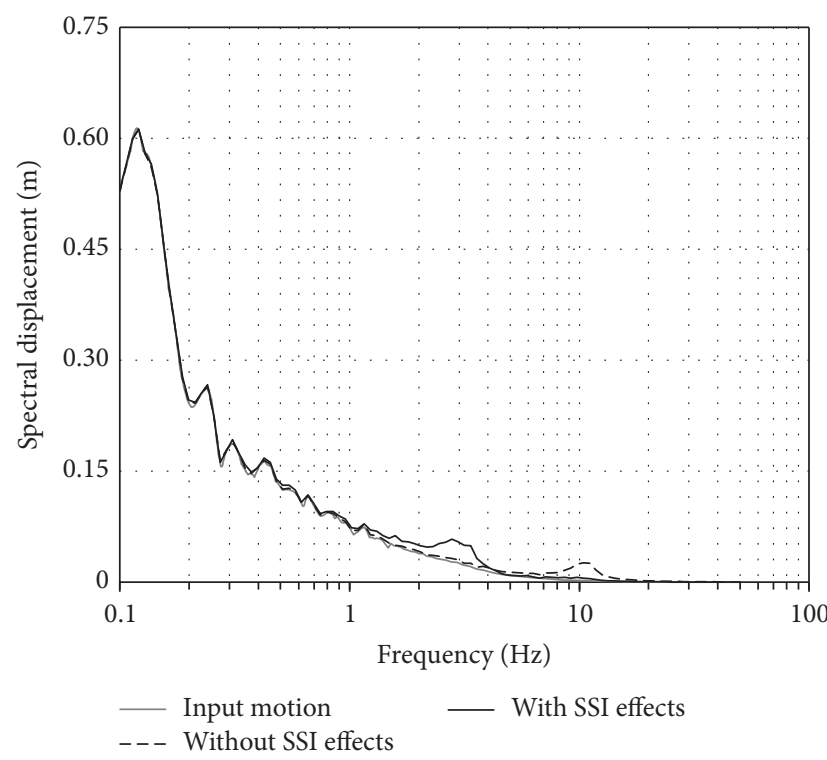

(a) At the top of the Reactor Containment Building

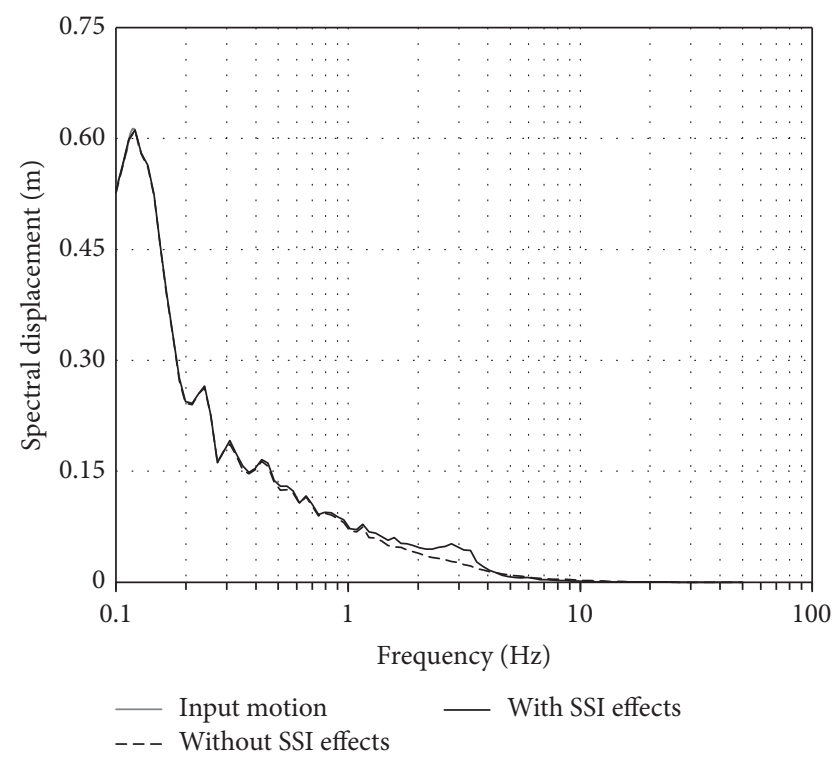

(b) At the bottom of the Reactor Containment Building

FIGURE 20: Comparison of the response spectral displacement with and without SSI effects under vertical excitation.

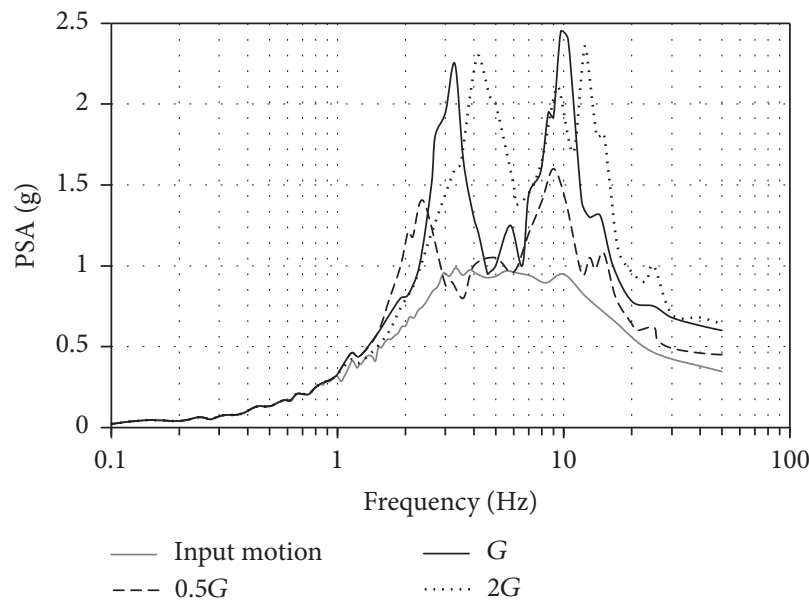

(a) At the top of Reactor Containment Building



(b) At the bottom of Reactor Containment Building

FIGURE 21: Comparison of response spectra acceleration under vertical excitation for different soil shear modulus.

the in-structure response spectral displacement with and without SSI effects. In terms of the difference between linear and equivalent-linear SSI analyses, it is clear that the former underestimates the in-structure response of the NPP structures. The response spectra from the iteration analysis using the maximum displacement as the iteration variable are smaller for some frequency ranges and greater for other frequency ranges than those from the iteration analysis using the equivalent displacement as the iteration variable.

(2) For the vertical excitation, considering the SSI effect results in a reduction of the PSA for a majority of the frequency range. This suggests that soil acts as an isolation system in the vertical direction to a certain degree. The difference between the instructure response spectral displacement with and without SSI effects is concentrated at frequencies near the natural frequencies of the structure and the soil field frequency. The SSI effects enlarge the response spectral displacement at the soil field frequency, while reducing the response spectral displacement at the natural frequencies of the structure.

(3) Reducing the shear modulus of soil results in increasing the amplification of PSA in horizontal direction from the bottom to the top of the Reactor Containment Building and reducing the effectiveness of the isolators. 




(a) At the top of Reactor Containment Building

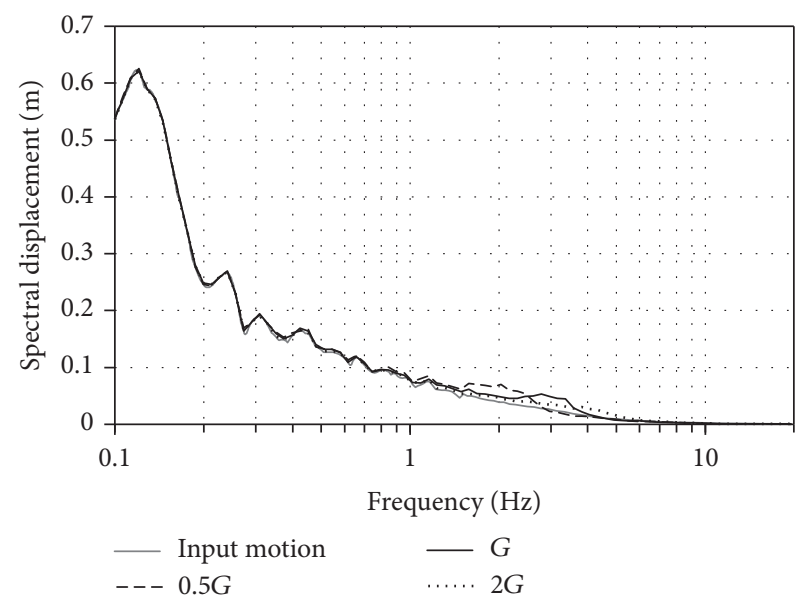

(b) At the bottom of Reactor Containment Building

FIGURE 22: Comparison of response spectra displacement under vertical excitation for different soil shear modulus.

(4) For the isolated NPP model studied, softer soil will result in higher PSA in horizontal direction and lower PSA in vertical direction over a substantial range of frequencies. In addition, softer soil acts as an isolation system in the vertical direction to a certain degree.

(5) The soil profile properties and isolator properties directly affect the effectiveness of the isolation system.

Linear and equivalent-linear analyses using frequency domain method were performed in this study to consider the bilinear property of isolators according to the past experience in nuclear industry. However, it is beneficial that full nonlinear analysis is performed in time domain and that several dozens of ground motions are taken as input to determine response range in the future research.

\section{Competing Interests}

The authors declare that they have no competing interests.

\section{Acknowledgments}

The authors wish to gratefully acknowledge the support of this work by the National Natural Science Foundation of China under Grant no. 51478357, a collaborative research project under International Joint Research Laboratory of Earthquake Engineering (ILEE) under Grant no. 0200121005/012, and the National Science \& Technology Pillar Program of China under Grant no. 2015BAK17B04.

\section{References}

[1] F. Naeim and J. Kelly, Design of Seismic Isolated Structures: From Theory to Practice, John Wiley \& Sons, New York, NY, USA, 1999.

[2] IAEA, "Verification of analysis methods for predicting the behavior of seismically isolated nuclear structures, final report of a coordinated research project 1996-1999," Tech. Rep. IAEATECDOC-1288, IAEA, Vienna, Austria, 2002.
[3] C. Medel-Vera and T. Ji, "Seismic protection technology for nuclear power plants: a systematic review," Journal of Nuclear Science and Technology, vol. 52, no. 5, pp. 607-632, 2015.

[4] M. Forni, A. Poggianti, F. Bianchi et al., "Seismic isolation of the IRIS nuclear plant," in Proceedings of the ASME Pressure Vessels and Piping Conference (PVP '09), pp. 289-296, Prague, Czech Republic, July 2009.

[5] R. Lo Frano and G. Forasassi, "Isolation systems influence in the seismic loading propagation analysis applied to an innovative near term reactor," Nuclear Engineering and Design, vol. 240, no. 10, pp. 3539-3549, 2010.

[6] Z. G. Zhou, J. Wong, and S. Mahin, "Potentiality of using vertical and three-dimensional isolation systems in nuclear structures," Nuclear Engineering and Technology, vol. 48, no. 5, pp.1237-1251, 2016.

[7] F. Perotti, M. Domaneschi, and S. De Grandis, "The numerical computation of seismic fragility of base-isolated Nuclear Power Plants buildings," Nuclear Engineering and Design, vol. 262, pp. 189-200, 2013.

[8] S. De Grandis, M. Domaneschi, and F. Perotti, "A numerical procedure for computing the fragility of NPP components under random seismic excitation," Nuclear Engineering and Design, vol. 239, no. 11, pp. 2491-2499, 2009.

[9] B. Basu, O. S. Bursi, F. Casciati et al., "A European association for the control of structures joint perspective. Recent studies in civil structural control across Europe," Structural Control and Health Monitoring, vol. 21, no. 12, pp. 1414-1436, 2014.

[10] M. C. Constantinou and M. C. Kneifati, "Dynamics of soil-baseisolated-structure systems," Journal of Structural Engineering, vol. 114, no. 1, pp. 211-221, 1988.

[11] L.-H. Zou, R.-D. Zhao, and J.-C. Zhao, "Analysis of the response to earthquake of the pile-soil-isolated structure interaction," Chinese Journal of Geotechnical Engineering, vol. 26, no. 6, p. 782, 2004 (Chinese).

[12] Z. Song and H. Ding, "The analysis of seismic response for baseisolated structure by LS-DYNA," in Proceedings of the 14th World Conference on Earthquake Engineering (WCEE '08), Beijing, China, October 2008.

[13] C. C. Spyrakos, I. A. Koutromanos, and C. A. Maniatakis, "Seismic response of base-isolated buildings including soil-structure 
interaction," Soil Dynamics and Earthquake Engineering, vol. 29, no. 4, pp. 658-668, 2009.

[14] H. P. Gavin and R. L. Nigbor, "Performance of the base-isolated Christchurch women's hospital in the Sep. 42010 Dar field earthquake and the Feb.22 2011 Christchurch earthquake," in Proceedings of the 20th Analysis and Computation Specialty Conference (ASCE '12), pp. 554-563, Chicago, Ill, USA, March 2012.

[15] S. Mahmoud, P.-E. Austrell, and R. Jankowski, "Simulation of the response of base-isolated buildings under earthquake excitations considering soil flexibility," Earthquake Engineering and Engineering Vibration, vol. 11, no. 3, pp. 359-374, 2012.

[16] Z. Zhou, S. Nicholas, and S. Mahin, "Effects of soil-structure interaction on seismically isolated nuclear power plant," in Proceedings of the 22th International Conference on Structural Mechanics in Reactor Technology, San Francisco, Calif, USA, August 2013.

[17] I. Politopoulos, I. Sergis, and F. Wang, "Floor response spectra of a partially embedded seismically isolated nuclear plant," Soil Dynamics and Earthquake Engineering, vol. 78, pp. 213-217, 2015.

[18] M. Sayed, D. Kim, and S. Cho, "Seismic analysis of base isolated nuclear power plant considering nonlinear pile-soil interaction," in Proceedings of the 22th International Conference on Structural Mechanics in Reactor Technology, San Francisco, Calif, USA, August 2013.

[19] American Society of Civil Engineers (ASCE), ASCE 4-98 Seismic Analysis of Safety-Related Nuclear Structures and Commentary, ASCE, Reston, Va, USA, 1998.

[20] Nuclear Regulatory Commission (NRC), NUREG-0800/Standard Review Plan for the Review of Safety Analysis Reports for Nuclear Power Plants, NRC, 2012.

[21] M. Tabatabaie, "Frequency/time domain hybrid approach for nonlinear SSI analysis," in Proceedings of the Workshop on Analytical Methods for Seismic SSI Analysis, PEER, UC Berkeley, January 2013.

[22] A. Whittaker, Y. Huang, and R. Mayes, "Seismic isolation of safety-related nuclear structures," in Proceedings of the Structures Congress, Las Vegas, Nev, USA, April 2011.

[23] J. Lysmer, F. Ostadan, M. Tabatabaie, S. Vahdani, and F. Tajirian, A System for Analysis of Soil-Structure Interaction, Theoretical Manual, University of California, Berkeley, Berkeley, Calif, USA, 1988.

[24] F. Ostadan, SASSI2000/A System for Analysis of Soil-Structure Interaction, Version 3, User's Manual, University of California, Berkeley, Berkeley, Calif, USA, 2007.

[25] P. B. Schnabel, J. Lysmer, and H. B. Seed, "SHAKE-a computer program for earthquake response analysis of horizontally layered sites," Tech. Rep. EERC 72-12, Earthquake Engineering Research Center, University of California, Berkeley, Berkeley, Calif, USA, 1972. 


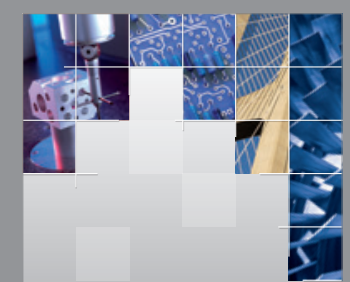

\section{Enfincering}




The Scientific World Journal

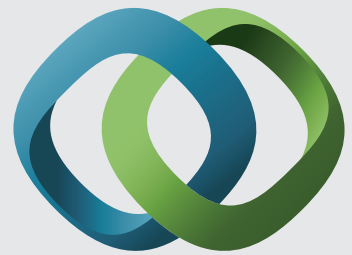

\section{Hindawi}

Submit your manuscripts at

http://www.hindawi.com
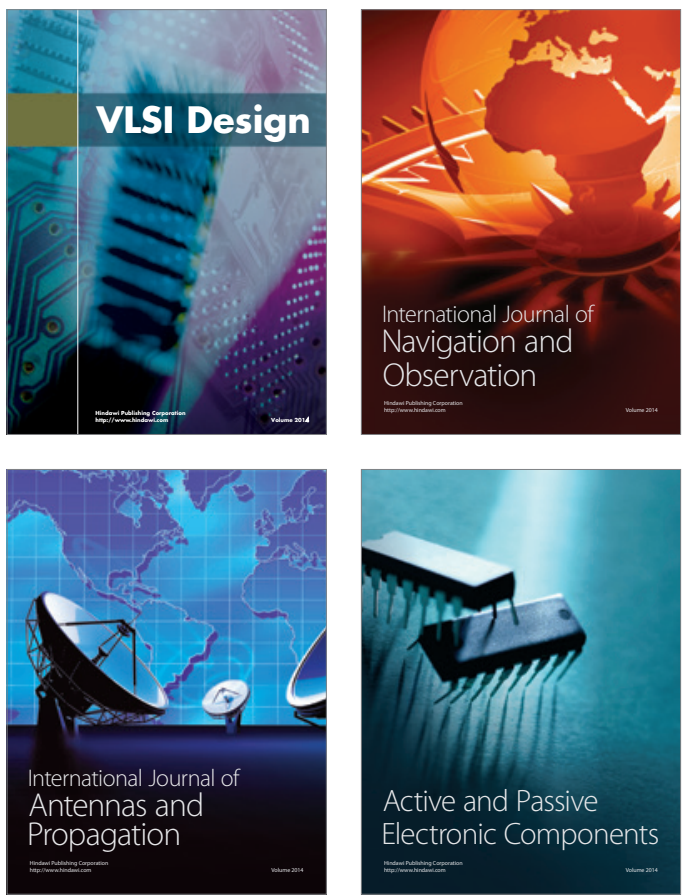
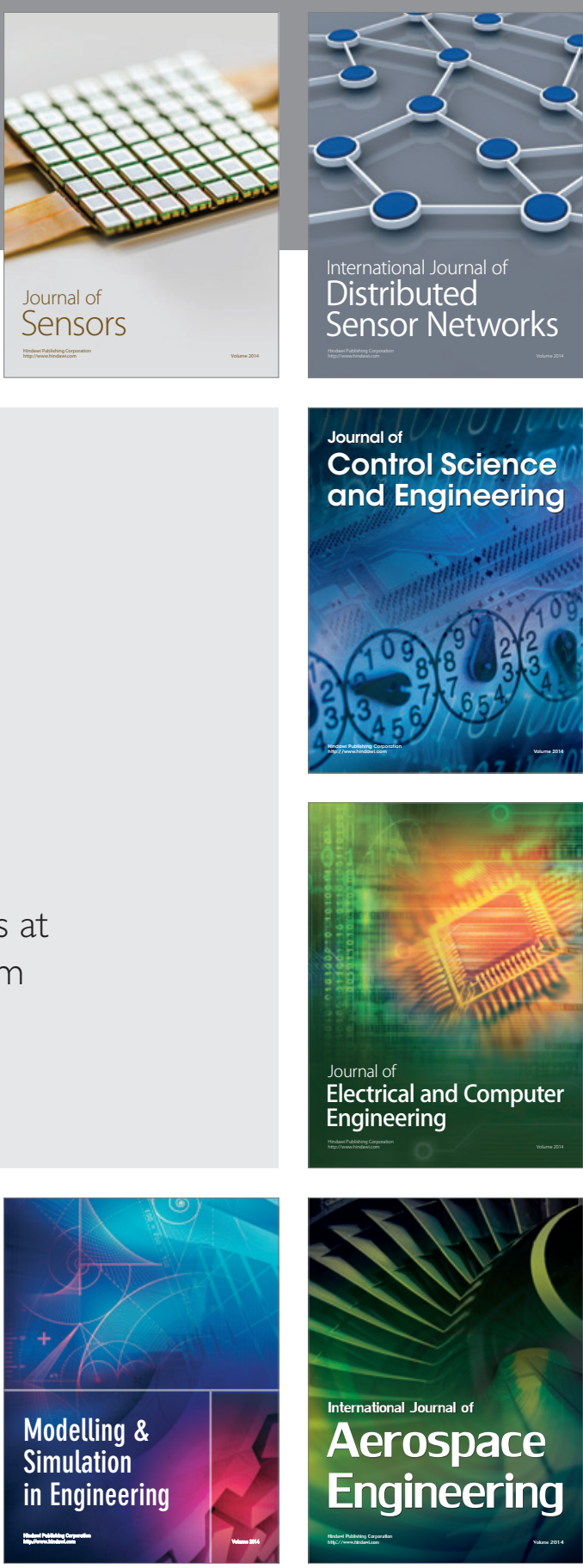

International Journal of

Distributed

Sensor Networks

Journal of

Control Science

and Engineering
